\title{
Isolated Body Lateropulsion in Supplementary Motor Area Infarction
}

\author{
Kunihiro Ueda, Akiko Seto, Tatsuo Mano and Tatsushi Toda
}

Key words: isolated body lateropulsion, supplementary motor area, magnetic resonance imaging, stroke

(Intern Med 59: 3113-3114, 2020)

(DOI: 10.2169/internalmedicine.5320-20)

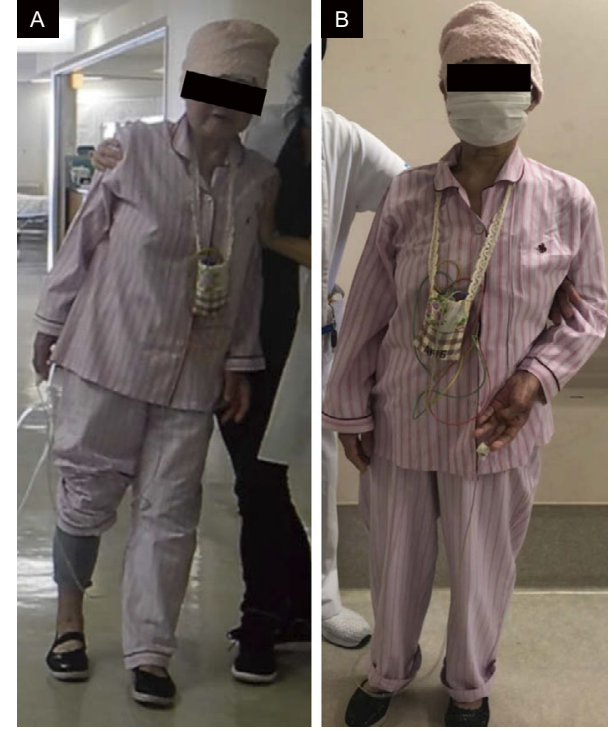

Picture 1.
A 71-year-old woman with pancreatic cancer and liver metastasis presented with transient left-leg weakness. On admission, while her weakness had disappeared, she fell when she attempted to stand. Neurological examination showed lateropulsion to the left (Picture 1A). Brain magnetic resonance imaging revealed an acute infarct in the right anterior cerebral artery territory, which included the supplementary motor area (SMA), not the primary motor area (Picture 2). Although anticoagulation therapy and rehabilitation improved her symptoms partially within a few days (Picture 1B), she later-developed Trousseau's syndrome, causing her motor function to deteriorate further. Isolated body lateropulsion (iBL) is a relatively rare neurological deficit that occurs due to lesions in the spinocerebellar tract, descending lateral vestibulospinal tract, vestibulo-thalamic pathway, dentatorubrothalamic pathway, or thalamocortical fascicle (1). SMA damage is an uncommon cause of iBL,

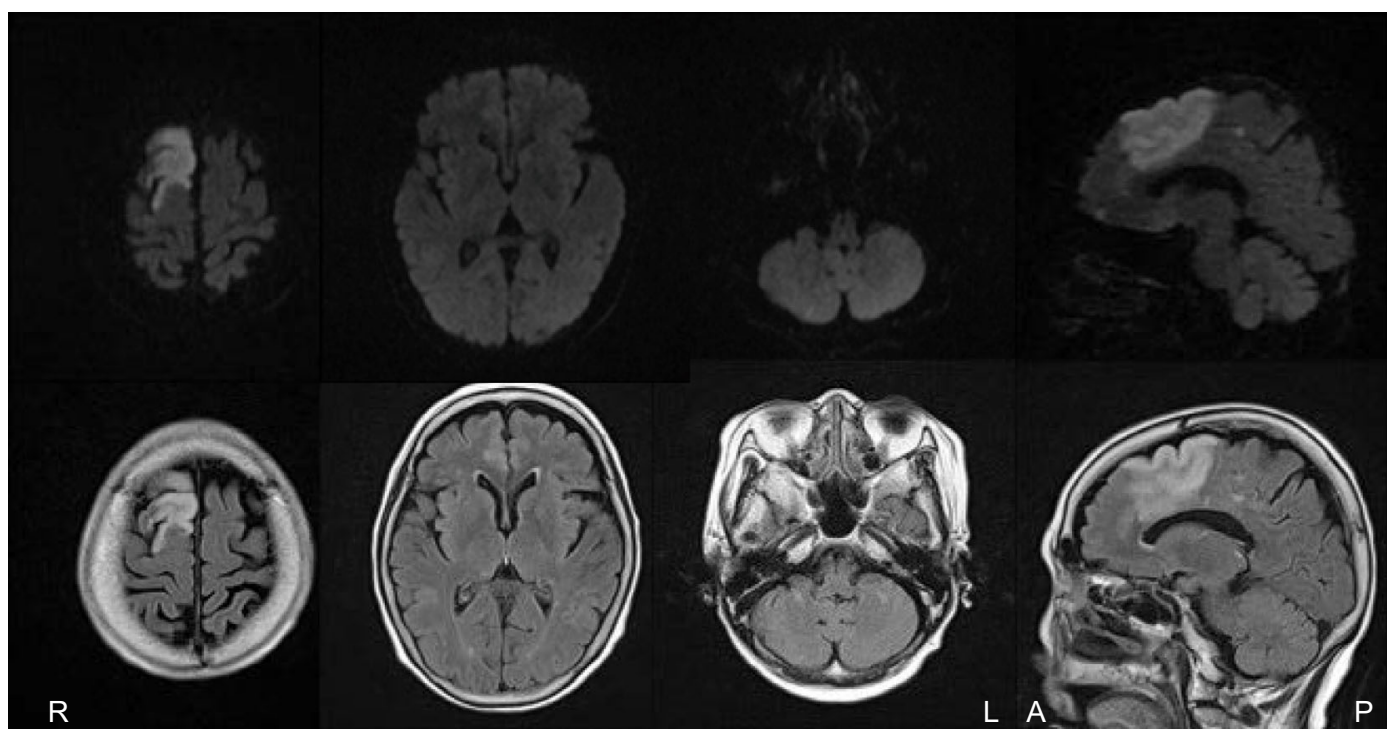

Picture 2.

Department of Neurology, Graduate School of Medicine, The University of Tokyo, Japan

Received: May 12, 2020; Accepted: June 22, 2020; Advance Publication by J-STAGE: August 4, 2020

Correspondence to Dr. Tatsuo Mano, tatsuomano@me.com 
with the impaired connection to the ventrolateral thalamus considered to be responsible (2). iBL is an infrequent but disabling condition that clinicians should be aware of.

The authors state that they have no Conflict of Interest (COI).

\section{References}

1. Nakazato Y, Tamura N, Ikeda K, Yamamoto T. Isolated body lateropulsion by lower lateral medullary infarction. eNeurologicalSci 7: 25-26, 2017.

2. Wada Y, Nishimura Y. Isolated astasia in acute infarction of the supplementary-motor area. BMJ Case Reports 2010: 2010.

The Internal Medicine is an Open Access journal distributed under the Creative Commons Attribution-NonCommercial-NoDerivatives 4.0 International License. To view the details of this license, please visit (https://creativecommons.org/licenses/ by-nc-nd/4.0/).

(C) 2020 The Japanese Society of Internal Medicine Intern Med 59: 3113-3114, 2020 